\title{
Internet publishing camps renew hostilities
}

\section{Colin Macilwain, New York}

The simmering tension between commercial publishers and those who believe that scientific literature should be available free on the Internet boiled over last week - at a meeting held to promote dialogue between the two groups.

Disagreement was fuelled by the news that six months after the US National Institutes of Health (NIH) launched PubMed Central (PMC) - a forum for the open posting on the Internet of research results already published elsewhere - few scientists are so far using the site.

At a meeting held at the New York Academy of Medicine, Pieter Bolman, president of Academic Press, one of the leading commercial publishers, said that PMC had been "asking for trouble" by trying to change simultaneously both the dominant distribution and business models for the communication of scientific information.

Bolman said that CrossRef, an information-exchange network agreed by publishers last November (see Nature 402, 226; 1999), contained a thousand times as much published material as PMC. He suggested that the latter, having "served its purpose" by helping to catalyse CrossRef (of which Nature is a member), should abandon its wider ambitions and join the publishers' network.

But advocates of PubMed Central say the site still has time to develop an audience.

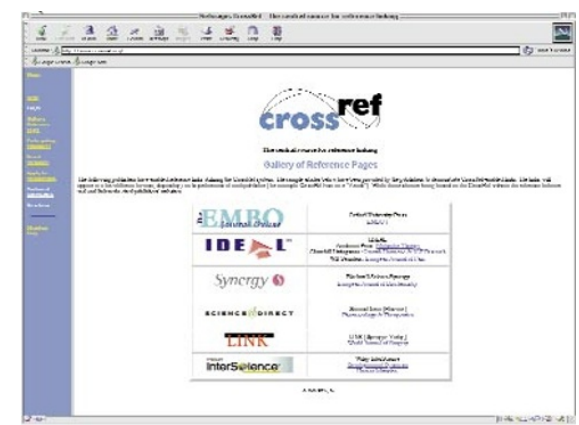

In front? The publishers' CrossRef claims to be outstripping the NIH's PubMed Central.

They express confidence that the participation of new publishing projects committed to open access - such as BioMedNet Central, part of the UK-based Current Science Group, which organized the meeting - will soon bring it new momentum.

Pat Brown, a geneticist at Stanford University and early advocate of PubMed Central, called on scientists to "take full control of the publishing process" and "insist that it is free, untaxed by the parasites in the publishing world".

Harold Varmus, president of the Memorial Sloan-Kettering Cancer Center in New York and former director of the NIH, said that PubMed Central had met with more resistance than he had anticipated. He told the meeting that the project's basic vision was unchanged, but that "what we've retreated to, or I should say progressed to, is a shortterm view" of the project as "a public vehicle, with government finance, to help distribute information that is in existing journals".

Varmus says that researchers want to browse top journals - which he expects will survive - but to search systematically the material that currently appears in a vast array of middle-ranking journals. "BioMed Central is going to have a devastating impact on the mid-ranking journals," he says.

Faced with the prediction that many scientific societies' journals will not survive the resulting fall in individual subscriptions, some speakers defended the editorial function of such journals.

George Lundberg, for example, former editor of the Journal of the American Medical Association and editor-in-chief of Medscape, an Internet-based medical database, said that the editor's role, "which much of [this] discussion is intended to abolish, sits at the middle" of scientific publishing.

And Marc Brodsky, executive director of the American Institute of Physics, predicted that BioMed Central, with its plans for 'open' peer review and its inclination to publish most of what it receives, would end up publishing material akin to conference proceedings - which, he says, are "not looked on very well" by the scientific community. it htt://pubmedcentral.nih.gov

\section{US scientists seek more funds for high-tech equipment}

\section{Paul Smaglik, Washington}

The largest professional body representing US researchers in the life sciences is urging the National Institutes of Health (NIH) to nearly quadruple its contribution to a scheme that helps investigators pay for equipment costing over $\$ 100,000$.

A survey carried out by the Federation of American Societies for Experimental Biology (FASEB) found that about threequarters of the $508 \mathrm{NIH}$-supported scientists who replied felt that the scheme, known as the Shared Instrumentation Grants (SIG) programme, is inadequately funded and managed.

Almost half of the respondents to the survey, the results of which were released in Washington this week, said a lack of financial support meant that their laboratories were not able to add research technologies as fast as they would like.

Although the NIH's overall budget has risen by 15 per cent in each of the last two years, FASEB points out that money for equipment has not kept pace. In particular, the SIG programme, which allows researchers already supported by NIH grants to split the cost of equipment costing over $\$ 100,000$, has fallen in real terms over the past decade.

SIG was funded at $\$ 32.5$ million for the financial year 1990 and $\$ 43.1$ million in 2000; it suffered during the budget restrictions of the early 1990s and is only now beginning to recover. FASEB recommends that the programme receive $\$ 150$ million in the financial year 2001.

Researchers are concerned about their ability to pay for the high-tech - and expensive - techniques on which they increasingly depend. In the past, such sentiments have been mostly anecdotal, so FASEB launched its survey last autumn to unearth more concrete evidence. The survey found that $84 \%$ of the respondents said that shared equipment was "extremely important" for their research.

David Speicher, the study's lead author, calls the \$150 million demand "pretty conservative", as it is based only on the number of investigators receiving R01 grants from the NIH.

"The scientific endeavour is moving in a direction where modern, expensive equipment is essential," says Speicher, a professor of structural biology at the Wistar Institute in Philadelphia. "If you don't have the equipment, it impairs the research."

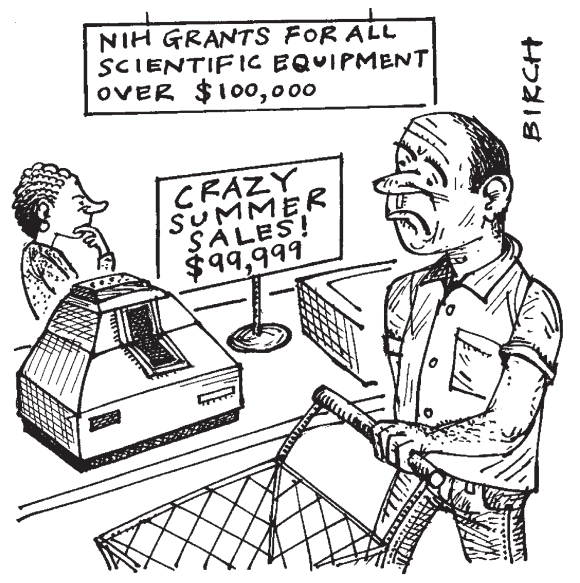

